\title{
Lymphocyte Subpopulations in Patients With Neurofibromatosis Type 1-associated Optic Pathway Gliomas and Plexiform Neurofibromas
}

\author{
AGATA MARJANSKA, MALGORZATA KUBICKA, BEATA KURYLO-RAFINSKA, \\ AGNIESZKA JATCZAK-GACA, MARIUSZ WYSOCKI and JAN STYCZYNSKI \\ Department of Pediatric Hematology and Oncology, Nicolaus Copernicus University Torun, \\ Jurasz University Hospital, Collegium Medicum, Bydgoszcz, Poland
}

\begin{abstract}
Background/Aim: Neurofibromatosis type 1 (NF1) is characterized by the occurrence of multisystem tumors, among which the most characteristic are optic pathway gliomas (OPGs) and plexiform neurofibromas (PNFs). With the development of new anticancer drugs targeting the immune system, it is important to examine the immunological status of patients with NF1. Furthermore, the immune system has been suggested as a probable modulator of NF1associated phenotypes. The objective of this study was the analysis of lymphocyte subset populations with respect to the presence of PNFs and OPGs. Patients and Methods: Fiftythree patients with NF1 diagnosed with OPG/PNF were analyzed for lymphocyte subpopulations. Results: Significantly lower levels of B-cells, T-cells and natural killer (NK) cells were observed in the group of patients with PNFs compared to those with OPG. Conclusion: Our observation may indicate a correlation between weakened functioning of the immune system and the formation of PNFs.
\end{abstract}

Neurofibromatosis type 1 (NF1) is a genetically determined neurocutaneous disease affecting about one in 3,000 people worldwide $(1,2)$. The diagnosis of NF1 is based on the clinical criteria set by the National Institutes of Health (NIH) and includes café au lait macules, freckling of the flexural areas, neurofibromas, iris hamartomas, optic gliomas, distinctive osseous lesions and a first-degree relative with NF1 (3). The disorder is characterized by the presence of

Correspondence to: Agata Marjanska, MD, Department of Pediatric Hematology and Oncology, Collegium Medicum, Nicolaus Copernicus University, Antoni Jurasz University Hospital No. 1, ul. Sklodowskiej-Curie 9, 85-094 Bydgoszcz, Poland. Tel: +48 525854860, Fax: +48 525854087, e-mail: agata.marjanska@wp.pl

Key Words: Neurofibromatosis type 1, lymphocyte subpopulations, $\mathrm{NF} 1$, plexiform neurofibroma, optic pathway glioma. multisystem tumors throughout the nervous system and skin, among which the most characteristic are optic pathway gliomas (OPGs) and plexiform neurofibromas (PNFs) $(4,5)$. OPG affects about $15 \%$ of patients with NF1 and usually arises during the first decade of life. Although OPG generally shows slow growth dynamics, it may present a dangerous evolution with severe impairment of visual function and potentially life-threatening behavior. The treatment options for OPGs are limited to a classical chemotherapeutic regimen that often shows poor outcome concerning visual outcome $(6,7)$. Nearly $30-50 \%$ of individuals with NF1 develop PNFs, that can undergo malignant transformation to malignant peripheral nerve sheath tumors (MPNSTs) in 5-10\% of patients (8). Clinically, in addition to their contribution to MPNST pathogenesis, PNFs are a significant cause of morbidity due to their propensity for local invasion, organ compression, bone erosion, chronic pain and untoward esthetics (9).

The unsatisfactory response to available systemic treatment modalities underscores the need for more effective therapies in the treatment of NF1-associated tumors. With the recent development of new anticancer drugs targeting the immune system, it is important to examine the immunological status of patients with NF1 (10). Furthermore, the immune system has modernly been suggested as a probable modulator of NF1associated phenotypes (11). The first reports on the use of immunotherapy in OPGs and PNFs seem promising $(10,12,13)$. To our knowledge, no studies have been performed so far on the immunological status of non-treated patients with NF1 who present symptomatic OPG or PNF. The objective of this study was the analysis of lymphocyte subset populations with respect to the presence of the most common NF1-associated tumors.

\section{Patients and Methods}

Patients. Fifty-three non-treated patients with NF1, diagnosed with OPG or PNF were included in this study and underwent analysis for lymphocyte subpopulations. Exclusion criteria were: (i) $<2$ 
Table I. Lymphocyte subpopulations in patients with neurofibromatosis type 1-associated plexiform neurofibromas (PNF) and optic pathway gliomas $(O P G)$.

\begin{tabular}{|c|c|c|c|c|c|c|c|c|c|c|}
\hline \multirow[b]{2}{*}{$\begin{array}{l}\text { Lymphocyte } \\
\text { population }\end{array}$} & \multicolumn{3}{|c|}{ Median (range) } & \multirow[b]{2}{*}{$\begin{array}{l}\text { All groups } \\
p \text {-Value* }\end{array}$} & \multicolumn{2}{|c|}{$\begin{array}{c}\text { PNF vs. } \\
\mathrm{PNF}+\mathrm{OPG}\end{array}$} & \multicolumn{2}{|c|}{$\begin{array}{l}\mathrm{OPG}+v s \\
\mathrm{PNF}+\mathrm{OPG}\end{array}$} & \multicolumn{2}{|c|}{$\begin{array}{l}\text { OPG } v s . \\
\text { PNF }\end{array}$} \\
\hline & $\begin{array}{l}\mathrm{PNF}(\mathrm{n}=20) \\
(\text { cells } / \mu \mathrm{l})\end{array}$ & $\begin{array}{c}\text { OPG }(n=25) \\
(\text { cells } / \mu \mathrm{l})\end{array}$ & $\begin{array}{l}\mathrm{PNF}+\mathrm{OPG}(\mathrm{n}=8) \\
\quad(\mathrm{cells} / \mu \mathrm{l})\end{array}$ & & $\mathrm{RR}$ & $p$-Value** & $\mathrm{RR}$ & $p$-Value** & $\mathrm{RR}$ & $p$-Value ${ }^{* *}$ \\
\hline Lymphocytes & 2015 (887-3678) & 3335 (1486-10138) & 2065 (1190-3537) & 0.002 & 1.0 & 0.832 & 1.6 & 0.018 & 1.7 & 0.001 \\
\hline \multirow[t]{2}{*}{$\mathrm{CD}^{+}$(T-cells) } & $1295(495-2696)$ & $2381(960-5941)$ & $1241(680-2352)$ & 0.004 & 1.0 & 0.595 & 1.9 & 0.012 & 1.8 & 0.005 \\
\hline & $63.7(54.4-79.8)$ & $63.5(50.9-74.2)$ & $61.6(52.9-67.9)$ & 0.371 & 1.0 & 0.242 & 1.0 & 0.355 & 1.0 & 0.349 \\
\hline \multirow[t]{2}{*}{$\mathrm{CD} 4^{+}$} & $722(364-1707)$ & $1359(501-4278)$ & $709(350-1440)$ & 0.003 & 1.0 & 0.381 & 1.9 & 0.017 & 1.9 & 0.003 \\
\hline & $40.0(28.9-49.6)$ & $36.9(26.3-48.4)$ & $37.5(27.2-40.7)$ & 0.287 & 1.1 & 0.115 & 1.0 & 0.389 & 0.9 & 0.367 \\
\hline \multirow[t]{2}{*}{$\mathrm{CD}^{+}$} & $446(118-926)$ & $740(256-1561)$ & 447 (246-799) & 0.009 & 1.0 & 0.958 & 1.7 & 0.027 & 1.7 & 0.006 \\
\hline & $22.2(11.2-30.8)$ & $20.8(12.5-29.4)$ & $22.2(19.3-23.4)$ & 0.980 & 1.0 & 0.859 & 0.9 & 0.883 & 0.9 & 0.909 \\
\hline \multirow[t]{2}{*}{ CD19+ (B-cells) } & $324(123-689)$ & $836(202-2940)$ & $423(98-569)$ & 0.003 & 0.8 & 0.958 & 2.0 & 0.029 & 2.6 & 0.002 \\
\hline & $18.5(7.5-26.5)$ & $22.6(12.4-35.7)$ & $16.9(7.6-28.2)$ & 0.098 & 1.1 & 0.899 & 1.3 & 0.153 & 1.2 & 0.047 \\
\hline \multirow{2}{*}{ 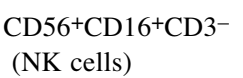 } & $225(4-534)$ & $370(104-1156)$ & $268(186-473)$ & 0.030 & 0.8 & 0.184 & 1.4 & 0.488 & 1.6 & 0.009 \\
\hline & $10.3(0.3-27.5)$ & $10.5(3.9-25.4)$ & $13.9(8.6-36.8)$ & 0.296 & 0.7 & 0.186 & 0.8 & 0.136 & 1.0 & 0.732 \\
\hline $\begin{array}{l}\mathrm{CD}^{+}{ }^{+} \mathrm{CD}^{+} \text {: } \\
\mathrm{CD}^{+}{ }^{+} \mathrm{CD}^{+} \text {ratio }\end{array}$ & $1.7(1.1-4.2)$ & $1.7(1.0-3.4)$ & $1.7(1.2-1.9)$ & 0.752 & 1.0 & 0.491 & 1.0 & 0.569 & 1.0 & 0.714 \\
\hline
\end{tabular}

RR: Relative ratio; NK: natural killer. *Kruskal-Wallis test; **Mann-Whitney test. Bold values show significance.

NIH criteria for the diagnosis of NF1, (ii) no OPG or PNF diagnosed, (iii) pharmacological treatment of the tumor, (iv) current infection or other acute disease that might cause false distribution of lymphocyte subpopulations. Each patient was assigned to one of three subgroups: presence of PNF alone, with OPG alone, and with both types of tumor. All patients were accrued between 01.09.2017-31.01.2018. Informed consent was obtained from the patients or their parents. The study was performed according to the institutional guidelines and was approved by the Institutional Review Board (approval number KB647/2017).

Determination of lymphocyte subsets and kinetics of lymphocyte reconstitution. Lymphocyte subpopulations were analyzed in peripheral blood by flow cytometry. The analysis was performed on FACS Canto II flow cytometer with CellQuest Pro software (Becton Dickinson, BD Biosciences, San Jose, CA, USA). Monoclonal antibodies used were the classic T- (anti-CD3, CD4 and CD8), B- (anti-CD19) and natural killer (NK)-cell antigens (anti-CD56 and CD16) (Becton Dickinson, BD Biosciences). At least 10,000 cells were analyzed in each case. At least two measurements were made for each patient, and the mean value was used. The absolute numbers and proportions of B-, T-, NK and CD4+/CD8 ${ }^{+}$lymphocytes were calculated from total number of peripheral blood lymphocytes. The $\mathrm{CD} 3+\mathrm{CD} 4+/ \mathrm{CD} 3+\mathrm{CD} 8+$ ratio was also analyzed for each patient. The relative ratio (RR) was calculated from median values of selected parameters for the respective groups.

Statistical analysis. Baseline parameters were compared between groups using Mann-Whitney or Kruskal-Wallis tests for quantitative variables, and chi-squared or Fisher's exact tests for frequencies. All the tests were two-sided. Statistical significance was defined as $p<0.05$.

\section{Results}

Demographics and clinical profile. A total of 53 patients qualified for the study, including 25 male (47.2\%) and 28 female $(52.8 \%)$, with a median age of 11.3 (range=1.8-68.7) years. Patients with NF1 were diagnosed as having PNF alone in $37.7 \%$ (20/53), OPG alone in $47.2 \%$ (25/53), and both PNF with OPG in $15.1 \%(8 / 53)$ of cases. PNFs were observed in $45 \%(9 / 20)$ of males and $55 \%(11 / 20)$ of females, at a median age of 18.2 (range $=5.6-68.7$ ) years. OPGs were found in $44 \%$ $(11 / 25)$ of males and $56 \%(14 / 25)$ of females, at a median age of 7.9 (range $=1.8-47.5$ ) years. Tumors of both types were diagnosed in $62.5 \%(5 / 8)$ of males and $37.5 \%(3 / 8)$ of females, at a median age of 11.4 (range $=6.3-60.9)$ years.

Lymphocyte subpopulations. Statistically significant differences between lymphocyte counts in peripheral blood of patients were demonstrated (Table I). Significantly lower levels of B-, T- and NK cells were observed in the group of patients with PNFs compared to the group with OPG. Significantly lower densities of B- and T-cells were also found in the group with both types of tumors compared to the group with OPG alone. There were no statistically significant differences between lymphocyte counts in patients with PNFs in the subgroups with and without OPG.

\section{Discussion}

T-Lymphocytes play a critical role in the anticancer response (14). Quantitative lymphocyte changes are prevalent in 
patients with cancer, and strongly affect prognosis and survival. The development of cancer in immunosuppressed individuals has demonstrated the contribution of different Tcell populations to the control of carcinoma occurrence (15). The presence of peripheral immune modifications in oncologicaI patients was shown in gastrointestinal cancer (15, 16). Lymphopenia was demonstrated in $3 \%$ of patients with localized disease and in $>20 \%$ individuals with different types of advanced cancer (sarcomas, pancreatic cancer, breast cancer, melanoma malignum, non-Hodgkin's lymphoma). $\mathrm{CD}^{+}{ }^{+}$lymphopenia was mainly observed in metastatic stages, but functional attenuation of memory T-cells, NK cells and monocytes was detected in patients with breast cancer, hepatocellular carcinoma and colon carcinoma with localized primary tumors (15). In analysis with immunodeficiency HIV-infected or post-transplantation patients, a higher incidence of cancer was described (17).

Farschtschi et al. evaluated the immune phenotypes in 37 patients with NF1 and associated these phenotypes with the volumes of various tumors types. No significant differences were demonstrated between the NF1 individuals and the nonNF1 control group for any of the T-cell subpopulations (11). It was observed that levels of $\mathrm{CD}^{+} / \mathrm{CD} 27^{-} \mathrm{T}$-cells in patients without tumor were lower than in those with NF1 with a low volume of tumor. Furthermore, an increased level of $\mathrm{CD} 8^{+} / \mathrm{CD} 7^{+} \mathrm{T}$-lymphocytes in subgroups of patients with NF1 with low and medium tumor volume was shown. The data suggest that the levels of $\mathrm{CD}^{+} / \mathrm{CD} 27^{-}$and $\mathrm{CD} 8^{+} / \mathrm{CD} 57^{+} \mathrm{T}$-cells can provide a helpful marker for the evaluation of tumor volume and subsequently for the risk of malignant transformation into MPNST.

B-Lymphocytes play a variety of roles in cancer immunity: they can contribute to tumor growth or participate in the antitumor response. Regulatory Blymphocytes represent a significant type of cell involved in the suppression of antitumor immunity. They weaken the antitumor response through the secretion of interleukin 10 with transforming growth factor $\beta$ and the conversion of resting $\mathrm{CD}^{+}$T-cells into regulatory $\mathrm{T}$-cells . Lymphotoxin produced by tumor-infiltrating B-cells may ensure an induction of angiogenesis in tumors. However, lymphotoxin can also promote tumor regression in other circumstances (18).

The pathogenesis of NF1-associated tumors is mainly dependent on incorrect RAS signaling, but some data suggest a role of the immune system in the development of cancer and an influence of immunological microenvironmental on response to treatment. For example, the number of tumorinfiltrating cytotoxic T-lymphocytes directly correlates with prognosis (19). In a few reports, immunological profiling of NF1-associated tumors was analyzed. These investigations potentially offer a way to guide the rational selection of immunotherapeutic treatments (19-21).
In our study, we observed lower levels of B-lymphocytes $\left(\mathrm{CD} 19^{+}\right)$, T-lymphocytes $\left(\mathrm{CD} 3^{+} \mathrm{CD} 4^{+} \mathrm{CD} 8^{+}\right)$and $\mathrm{NK}$ cells $\left(\mathrm{CD}^{+} 6^{+}\right)$in patients with NF1-associated PNF. These results may show that the function of the immune system in these patients with NF1 is impaired, which may correlate with a predisposition to the development of PNF. As far as we are aware of, there are no comparative reports.

In conclusion, significantly lower densities of B-, T- and NK cells were shown in peripheral blood of patients with NF1 and PNFs compared to those with OPG. This may indicate a correlation between the weakened functioning of the immune system and the formation of PNFs.

\section{Conflicts of Interest}

The Authors have no conflicts of interest to disclose in regard to this study.

\section{Authors' Contributions}

AM: Concept/design, data collection, data analysis/interpretation, writing article. MK, BKR, AJG, MW: Data collection, data analysis/interpretation, approval of article. JS: Concept/design, data analysis/interpretation, critical revision of article, approval of article.

\section{References}

1 Hirbe AC and Gutmann DH: Neurofibromatosis type 1: A multidisciplinary approach to care. Lancet Neurol 13(8): 834843, 2014. PMID: 25030515. DOI: 10.1016/S1474-4422(14) 70063-8

2 Tucker T, Friedman JM, Friedrich RE, Wenzel R, Funsterer C and Mautner VF: Longitudinal study of neurofibromatosis 1associated plexiform neurofibromas. J Med Genet 46(2): 81-85, 2009. PMID: 18930997. DOI: $10.1136 /$ jmg.2008.061051

3 Neurofibromatosis. Conference statement. National Institutes of Health Consensus Development Conference. Arch Neurol 45(5): 575-578, 1988. PMID: 3128965.

4 Marjanska A, Jatczak-Gaca A, Wojtkiewicz A, Wysocki M and Styczynski J: Demographical profile and spectrum of multiple malignancies in children and adults with neurocutaneous disorders. Anticancer Res 38(9): 5453-5457, 2018. PMID: 30194202. DOI: 10.21873/anticanres.12877

5 Karaconji T, Whist E, Jamieson RV, Flaherty MP and Grigg JRB: Neurofibromatosis type 1: Review and update on emerging therapies. Asia Pac J Ophthalmol 8(1): 62-72, 2018. PMID: 30387339. DOI: $10.22608 /$ APO.2018182

6 Trevisson E, Cassina M, Opocher E, Vicenzi V, Lucchetta M, Parrozzani R, Miglionico G, Mardari R, Viscardi E, Midena E and Clementi M: Natural history of optic pathway gliomas in a cohort of unselected patients affected by neurofibromatosis 1 . J Neurooncol 134(2): 279-287, 2017. PMID: 28577031. DOI: 10.1007/s11060-017-2517-6

7 Mehlan J, Schuttauf F, Salamon JM, Kordes U, Friedrich RE and Mautner VF: Manifestations and treatment of adult-onset symptomatic optic pathway glioma in neurofibromatosis type 1 . Anticancer Res 39(2): 827-831, 2019. PMID: 30711963. DOI: 10.21873/anticanres.13181 
8 Varin J, Poulain L, Hivelin M, Nusbaum P, Hubas A, Laurendeau I, Lantieri L, Wolkenstein P, Vidaud M, Pasmant E, Chapuis N and Parfait B: Dual mTORC1/2 inhibition induces anti-proliferative effect in NF1-associated plexiform neurofibroma and malignant peripheral nerve sheath tumor cells. Oncotarget 7(24): 35753-35767, 2016. PMID: 26840085. DOI: 10.18632/oncotarget.7099

9 Pemov A, Li H, Patidar R, Hansen NF, Sindiri S, Hartley SW, Wei JS, Elkahloun A, Chandrasekharappa SC, Program NCS, Boland JF, Bass S, Laboratory NDCGR, Mullikin JC, Khan J, Widemann BC, Wallace MR and Stewart DR: The primacy of NF1 loss as the driver of tumorigenesis in neurofibromatosis type 1-associated plexiform neurofibromas. Oncogene 36(22): 3168-3177, 2017. PMID: 28068329. DOI: 10.1038/onc.2016.464

10 Karmakar S and Reilly KM: The role of the immune system in neurofibromatosis type 1-associated nervous system tumors. CNS Oncol 6(1): 45-60, 2017. PMID: 28001089. DOI: 10.2217/cns-2016-0024

11 Farschtschi S, Park SJ, Sawitzki B, Oh SJ, Kluwe L, Mautner VF and Kurtz A: Effector T cell subclasses associate with tumor burden in neurofibromatosis type 1 patients. Cancer Immunol Immunother 65(9): 1113-1121, 2016. PMID: 27448806. DOI: 10.1007/s00262-016-1871-0

12 Wang S, Liechty B, Patel S, Weber JS, Hollmann TJ, Snuderl M and Karajannis MA: Programmed death ligand 1 expression and tumor infiltrating lymphocytes in neurofibromatosis type 1- and 2-associated tumors. J Neurooncol 138(1): 183-190, 2018. PMID: 29427150. DOI: 10.1007/s11060-018-2788-6

13 Deyle DR, Escobar DZ, Peng KW and Babovic-Vuksanovic D: Oncolytic measles virus as a novel therapy for malignant peripheral nerve sheath tumors. Gene 565(1): 140-145, 2015. PMID: 25843626. DOI: 10.1016/j.gene.2015.04.001

14 Yang X, Kang N, Toyofuku WM and Scott MD: Enhancing the proinflammatory anti-cancer $\mathrm{T}$ cell response via biomanufactured, secretome-based, immunotherapeutics. Immunobiology 224(2): 270-284, 2019. PMID: 30711357. DOI: 10.1016/j.imbio.2018. 12.003

15 Menetrier-Caux C, Ray-Coquard I, Blay JY and Ch. C: Lymphopenia in cancer patients and its effects on response to immunotherapy: An opportunity for combination with cytokines? J Immunother Cancer 7: 85, 2019. PMID: 30922400. DOI: 10.1186/s40425-019-0549-5
16 Bone $\mathrm{G}$ and Lauder I: Cellular immunity, peripheral blood lymphocyte count and pathological staging of tumours in the gastrointestinal tract. Br J Cancer 30(3): 215-221, 1974. PMID: 4451626. DOI: $10.1038 /$ bjc. 1974.184

17 Grulich AE, van Leeuwen MT, Falster MO and Vajdic CM: Incidence of cancers in people with HIV/AIDS compared with immunosuppressed transplant recipients: a meta-analysis. Lancet 370(9581): 59-67, 2007. PMID: 17617273. DOI: 10.1016/ S0140-6736(07)61050-2

18 Yuen GJ, Demissie E and Pillai S: B-Lymphocytes and cancer: A love-hate relationship. Trends Cancer 2(12): 747-757, 2016. PMID: 28626801. DOI: 10.1016/j.trecan.2016.10.010

19 Haworth KB, Arnold MA, Pierson CR, Choi K, Yeager ND, Ratner N, Roberts RD, Finlay JL and Cripe TP: Immune profiling of NF1-associated tumors reveals histologic subtype distinctions and heterogeneity: Implications for immunotherapy. Oncotarget 8(47): 82037-82048, 2017. PMID: 29137242. DOI: 10.18632 oncotarget.18301

20 Fletcher JS, Wu J, Jessen WJ, Pundavela J, Miller JA, Dombi E, Kim MO, Rizvi TA, Chetal K, Salomonis N and Ratner N: CXCR3-expressing leukocytes are necessary for neurofibroma formation in mice. JCI Insight 4(3): e98601, 2019. PMID: 30728335. DOI: $10.1172 /$ jci.insight. 98601

21 Shurell E, Singh AS, Crompton JG, Jensen S, Li Y, Dry S, Nelson S, Chmielowski B, Bernthal N, Federman N, Tumeh P and Eilber FC: Characterizing the immune microenvironment of malignant peripheral nerve sheath tumor by PD-L1 expression and presence of $\mathrm{CD}^{+}$tumor-infiltrating lymphocytes. Oncotarget 7(39): 64300-64308, 2016. PMID: 27588404. DOI: 10.18632 /oncotarget 